\title{
SELEÇÃO DE CLONES DE AMEIXEIRA PARA O SUL DO ESTADO DE MINAS GERAIS ${ }^{1}$
}

\author{
JOSÉ DARLAN RAMOS², OSCAR MARIANO HAFLE ${ }^{3}$, NILTON NAGIB JORGE CHALFUN ${ }^{4}$, \\ HENRIQUE ANTUNES DE SOUZA ${ }^{5}$, LUDMILLA DE LIMA CAVALLARI ${ }^{6}$
}

RESUMO - Um dos sérios problemas enfrentados pelos fruticultores é o reduzido número de cultivares disponíveis regionalmente. Nesse aspecto, a produção de novos materiais genéticos é uma alternativa viável e necessária para minimizar este entrave. O objetivo deste trabalho foi selecionar diferentes clones de ameixeira visando à obtenção de plantas com alta produtividade e frutos de boa qualidade, com maturação escalonada e adaptados às condições climáticas do sul de Minas Gerais. Foram selecionadas plantas de um antigo pomar comercial, localizado no Município de Wenceslau Braz - MG. Estas plantas estavam vegetando e produzindo em condições totalmente adversas, sem quaisquer tratos culturais. Após identificação, foram coletados dados fenológicos de coloração da flor, épocas de brotação e floração. Nos frutos, foram avaliados: época de maturação (início e fim), tamanho, forma, descrição da película, descrição da polpa, ocorrência de pragas e doenças. Após um período de avaliação de dois ciclos produtivos (1996-1997 e 1997-1998), foram selecionados clones com características favoráveis, principalmente com relação às épocas de floração e maturação dos frutos e adaptação ambiental. A maturação mais precoce ocorreu na seleção VI, enquanto a colheita se prolongou mais nas seleções I, VII, VIII e XI.

Termos para indexação: Prunus sp, melhoramento, seleção, clones, fenologia.

\section{SELECTION OF CLONES OF PLUMS FOR THE SOUTH OF THE STATE OF MINAS GERAIS}

\begin{abstract}
One of the serious problems faced by fruit growers is the low quantity of available cultivars regionally. The production of new genetic materials is a feasible and necessary alternative to minimize this obstacle. This work aimed to select different genetic materials of plums in order to obtain high productivity plants and high quality fruits, with assigned maturation and adapted to the climatic conditions for the Southern region of the state of Minas Gerais. Plants of an old orchard were selected, located in the district of Wenceslau Braz, Minas Gerais State, which were vegetating and producing in adverse agronomic conditions, without any cultural practices. The following phenological data were collected: flower color; sprouting and blooming. From fruits were evaluated: maturation (beginning and end), size, form, and skin and pulp description. After two productive cycles of evaluation (1996/1997 and 1997/1998) clones with desirable characteristics were identified, related to blooming, fruit maturation and environmental improvement. The precocious maturation occurred in the selection VI, while the longest harvest were selections I, VII, VIII and XI.
\end{abstract}

Index terms: Prunus sp, breeding, selection, clones, phenology.

\section{INTRODUÇÃO}

A ameixeira é uma das plantas que mais se difundiu pelo mundo, sendo cultivada em várias condições climáticas devido à grande quantidade de espécies existentes e do resultado de hibridações ocorridas ao longo do desenvolvimento da cultura (Castro, 2003). Segundo o Agrianual (2007), foi comercializado na CEAGESP-SP, em 2005, o volume de 26.444 toneladas de ameixa, com maiores ofertas nos meses de dezembro, janeiro e fevereiro.

Para a ameixeira, o frio é classificado como um dos parâmetros de maior importância, tanto para eliminar a dormência, como pelos prejuízos causados durante e após a floração. A necessidade de frio hibernal varia de 300 a 1.200 horas $\left(\leq 7,2{ }^{\circ} \mathrm{C}\right)$, para que haja uma satisfatória superação da dormência das gemas floríferas e vegetativas (Herter et al., 1997).

Pertencem à espécie Prunus salicina as cultivares comerciais mais importantes, por serem menos exigentes em frio (Lorenzi et al., 2006). No Brasil, há cerca de quinze cultivares de mesa que encontraram condições edafoclimáticas favoráveis ao seu desenvolvimento. Tais cultivares apresentam floração abundante, e, para a maioria delas, a polinização é fator preponderante para produção econômica de frutos, pois há necessidade de um polinizador para uma boa frutificação (Carvalho \& Raseira, 1990; Lorenzi et al., 2006).

Decorrente das seleções realizadas pelo Instituto Agronômico de Campinas, a ameixeira tornou-se uma das frutíferas de maior incremento nos últimos anos, no Estado de São Paulo e nas regiões de ecologia similar dos Estados vizinhos; esses frutos destinam-se principalmente ao consumo in natura

\footnotetext{
${ }^{1}$ (Trabalho 165-06). Recebido em: 24-10-2006. Aceito para publicação em: 02-07-2007.

Dr. Prof. Dep. de Agricultura da Universidade Federal de Lavras (UFLA), Cx. Postal 37, Lavras-MG, CEP 37200-000 -e-mail: darlan@ufla.br

2 Doutorando em Agronomia/Fitotecnia-UFLA. Professor da Escola Agrotécnica Federal de Sousa-PB, e-mail: omhafle@yahoo.com.br.

${ }^{3}$ Dr. Prof. Dep. de Agricultura/UFLA, Cx. Postal 37, Lavras-MG, e-mail: chalfum@ufla.br.

${ }^{4}$ Mestrando FCAV/UNESP, Jaboticabal-SP, e-mail: henrique.antuness@yahoo.com.br.

${ }^{5}$ Acadêmica do curso de Agronomia/UFLA, e-mail: milla.cavalllari@pop.com.br.
} 
no mercado interno (Ojima et al.,1992).

A região sul do Estado de Minas Gerais possui grande aptidão para inúmeras frutíferas, notadamente aquelas de clima temperado, onde a ameixeira encontra condições favoráveis para o seu desenvolvimento e produtividade (Nascimento, 1986). As variedades mais cultivadas na região são: Gema de Ouro, Roxa Japonesa e Reubenel (Antunes et al., 1997).

Os municípios que possuem áreas com altitudes próximas a $1.000 \mathrm{~m}$ em relação ao nível do mar, apresentam número de horas de frio necessário para a normal superação de dormência. Segundo Antunes et al. (1997), os municípios de Jacuí, São Sebastião do Paraíso, Pratópolis, Poços de Caldas, Passa Quatro e outros apresentam condições climáticas favoráveis à cultura. Um programa de melhoramento voltado para essas regiões permitiria a obtenção de cultivares adaptadas às diferentes condições de clima. Seriam melhoradas as cultivares existentes que apresentam boa produtividade, como é o caso da Roxa de Delfim Moreira, na qual é necessário aumentar o tamanho e a resistência ao transporte de seus frutos.

O objetivo deste trabalho foi selecionar acessos genéticos de ameixeira visando à obtenção de clones superiores e adaptados às condições climáticas do sul de Minas Gerais.

\section{MATERIAL E MÉTODOS}

A partir de agosto de 1994, iniciou-se um longo e detalhado levantamento geográfico de áreas onde eventualmente poderiam ser encontradas plantas promissoras de ameixeira. Foi detectada uma área em uma propriedade particular, no município de Wenceslau Braz - MG, latitude de $22^{\circ} 32^{\prime} \mathrm{S}$, longitude de $54^{\circ}$ 21' 46" WGr e altitude de $1.005 \mathrm{~m}$ a nível do mar, com clima do tipo Cwb, temperatura média anual em torno de $17^{\circ} \mathrm{C}$ e precipitação total anual de $1.409 \mathrm{~mm}$, sendo maior nos meses de dezembro e janeiro.

Nesse local, foram encontradas plantas remanescentes de um antigo pomar comercial, oriundo de propagação sexuada e assexuada. Essas estavam produzindo sob condições adversas, sem quaisquer tratos culturais. Após um período de avaliação de dois ciclos produtivos (1996-1997 e 1997-1998), foram selecionadas plantas com características favoráveis, principalmente com relação às épocas de floração, maturação dos frutos e sua qualidade comercial.

A partir dessas plantas, foram coletados os dados fenológicos de época de brotação, floração e cor da flor. Dos frutos, foram avaliados o período de maturação, tamanho, forma e descrição da película e polpa.

O início da floração, floração plena (FP) e fim da floração foram considerados quando a planta apresentava, respectivamente: $5 \%, 70 \%$ de flores abertas e mais de $50 \%$ das flores com suas pétalas caídas.

O início da brotação (IB) foi considerado quando aproximadamente $5 \%$ das gemas vegetativas, uniformemente distribuídas na planta, emitiram os primeiros primórdios foliares.

$\mathrm{O}$ período de amadurecimento dos frutos (PAF) foi o decorrido desde a maturação comercial dos primeiros até os últimos frutos, na planta.

As características físicas e organolépticas foram realizadas a partir de quatro amostras de cinco frutos, coletadas na altura mediana da copa, em cada um dos quadrantes da planta.

O tamanho do fruto (TF) foi determinado através de pesagem, sendo considerados pequenos os frutos com menos de $30 \mathrm{~g}$, médio entre 30-60g e grande mais de 60 g. Os resultados são as médias dos dois anos de avaliação.

Para a forma do fruto (FF), atribui-se a classificação de redondo e ovalado, conforme o aspecto apresentado pelo fruto no momento da pesagem.

Na descrição da película, foi caracterizada a cor e a espessura através de análise visual dos frutos e remoção cuidadosa da película.

Para a descrição da polpa, utilizou-se da cor e do sabor, através da observação visual e teste de prova degustativa das amostras.

Os onze acessos descritos neste trabalho foram propagados vegetativamente (enxertia) e compõem duas áreas experimentais, localizadas no pomar da Universidade Federal de Lavras (UFLA) e no Campo Experimental da Empresa de Pesquisa Agropecuária do Estado de Minas Gerais (EPAMIG), no município de Maria da Fé, onde estão sendo avaliadas as características morfológicas e fisiológicas da planta e dos frutos.

\section{RESULTADOS E DISCUSSÃO}

Todos os acessos apresentaram flores de coloração branca, com exceção da seleção XI, que apresentou flores de coloração roxa (Tabela 1).

A época de floração variou com o genótipo e o ano de observação, sendo que os mais precoces (com florescimento em julho e agosto), em ambos os anos, foram as seleções I, IV, VI, VII e XI. Os mais tardios (com florescimento em setembro) foram as seleções III, V, IX e X.

Em regiões de maior altitude do Estado de São Paulo, a maioria das cultivares de ameixeira florescem entre os meses de julho a setembro, variando com as alterações climáticas anuais e segundo os locais de cultivo. Porém, naqueles locais de altitudes máximas em que ocorrem invernos mais rigorosos, o florescimento pode ser retardado em até 30 dias (Barbosa et al., 1991)

Para Caldas-MG, Silva (2000) mostrou que as cultivares Gema de Ouro, Roxa de Itaquera, Grancuore, Reubennel, Kelsey 31, Harry Pickstone, Cower di Lion e Irati apresentaram comportamento de floração precoce ( $2^{\mathrm{a}}$ quinzena de julho a $1^{\mathrm{a}}$ quinzena de agosto) enquanto a cultivar Roxa Japonesa apresentou comportamento tardio ( $2^{\mathrm{a}}$ quinzena de agosto).

Entretanto, Grellmann \& Simonetto (1995), estudando cinco safras consecutivas de ameixeiras, em Veranópolis (RS), constataram que as cultivares Reubennel, Harry Pickstone, Ozark Premier e Santa Rosa florescem nos meses de julho/agosto; agosto/setembro; setembro/outubro e agosto/setembro, respectivamente.

Com relação ao comprimento do período de floração, as seleções IV, V e IX apresentaram-se maiores (10 a 12 dias) enquanto as seleções II, VI e VIII se apresentaram mais curtos (5 
a 6 dias). As brotações ocorreram mais cedo nos acessos I, VI e VII e mais tardiamente nas seleções III, IX e X.

O frio persistente durante a floração poderá causar distúrbios graves à polinização, ao processo de desenvolvimento do tubo polínico e à fusão dos núcleos (Herter et al., 2003), sendo as plantas de períodos curtos de floração mais sujeitas a estes danos climáticos. Além disso, períodos mais longos de floração promovem uma extensão no período de colheita, o que pode ser benéfico para o produtor.

Observando os dados da Tabela 2, verifica-se que a maturação mais precoce ocorreu na seleção VI (21-11), enquanto a colheita se prolongou mais nas seleções I, VII, VIII e XI ( $1^{\text {a }}$ quinzena de março). Os períodos mais longos de amadurecimento dos frutos (PAF) ocorreram nas seleções I, XI (83 dias), VII, VIII (75 dias) e os menores ocorreram na VI, X (21 dias), V (28 dias), IX (30 dias) e IV (35 dias). As seleções V e X apresentaram menor ciclo produtivo.

Segundo o Agrianual (2007), os melhores preços para a fruta, na CEAGESP-SP, são alcançados nos meses de outubro, novembro, dezembro e março, devido às menores ofertas no mercado. No Brasil, as colheitas ocorrem no período de novembro a março, variando conforme o local, a cultivar e a destinação da colheita. Assim, o grau de maturação dos frutos poderá variar consideravelmente se forem destinados ao consumo in natura ou para a indústria, ou até mesmo se forem armazenados para o consumo na entressafra.

Em estudo de cultivares de ameixeira, Alvarenga \& Fortes (1985) consideram precoces as cultivares Carmesin e Gema de Ouro, que podem ser colhidas em outubro e novembro; de colheita intermediária as cultivares Grancuore, Kelsey Paulista, Roxa de Itaquera e Santa Rosa, com maturação entre novembro e janeiro, e de colheita tardia as cultivares Santa Rita, Wickson e Burbank, com colheita de janeiro a abril.
O tamanho dos frutos variou de grandes para as seleções II e X, médios para I, III, VI, VII, VIII, IX e pequenos nas IV, V e XI.

Para trabalho realizado em Caldas-MG, Silva (2000) encontrou os maiores pesos nas cultivares Gema de Ouro e Grancuore (58,5 e 56,34 g) e os menores pesos para as cultivares Kesley 31 e Roxa Japonesa (33,53 e 33,25 g). As cultivares Roxa de Itaquera, Cower di Lion, Januária, Reubennel, Harry Pickstone e Irati apresentaram pesos intermediários que variaram de 49,68 a 41,28 g).

O tamanho e a forma do fruto são atributos importantes, pois a variação entre as unidades individuais de um produto pode afetar a escolha deste pelo consumidor, as práticas de manuseio, o potencial de armazenamento, a seleção de mercado e o destino final (Chitarra \& Chitarra, 2005), sendo um atributo de referência na escolha do produto pelo consumidor da fruta.

As seleções III e VI apresentam frutos de coloração vermelha e as seleções I, II, VII, VII e XI apresentaram coloração roxa. Os frutos de coloração forte e brilhante são os preferidos pelo consumidor (Chitarra \& Chitarra, 2005), podendo estes terem maior aceitação pelo consumidor.

A espessura da película apresentou-se grossa nas seleções VI, X, XI, podendo ser indicativo de que possam sofrer menos danos durante a colheita e manuseio, assim como terem um período de armazenamento mais prolongado.

O sabor detectado pela degustação variou de doce, doceacidulado e ácido nas diferentes seleções. De acordo com Chitarra \& Chitarra (2005), a relação açúcar/ácido é a forma mais utilizada para a avaliação do sabor. No entanto, há necessidade de avaliações mais objetivas (sólidos solúveis e acidez titulável), para uma melhor definição dessa característica, o que vem sendo realizada nos bancos de germoplasmas dessas seleções implantadas em Lavras e Maria da Fé.

TABELA 1 - Cor da flor (CF), período de floração (FLO), plena floração (PF), início da brotação (IB) e período de amadurecimento dos frutos (PAF) das plantas selecionadas situadas em Wenceslau Braz-MG / Períodos de 1996-1997 e 1997-1998.

\begin{tabular}{|c|c|c|c|c|c|c|c|c|c|}
\hline \multirow[t]{2}{*}{ Seleção } & \multirow[t]{2}{*}{$\mathbf{C F}$} & \multicolumn{4}{|c|}{ Ano de 1996} & \multicolumn{4}{|c|}{ Ano de1997 } \\
\hline & & FLO & PF & IB & PAF & FLO & PF & IB & PAF \\
\hline I & $\mathrm{Br}^{*}$ & $14 / 08-21 / 08$ & $17 / 08$ & $28 / 08$ & $15 / 12-07 / 03$ & $30 / 07-07 / 08$ & $03 / 08$ & $15 / 08$ & $01 / 12-21 / 02$ \\
\hline II & $\mathrm{Br}$ & 07/09-13/09 & $10 / 09$ & $21 / 09$ & $15 / 12-15 / 01$ & $22 / 08-29 / 08$ & $25 / 08$ & 06/09 & $01 / 12-01 / 01$ \\
\hline III & $\mathrm{Br}$ & 20/09-29/09 & $25 / 09$ & $06 / 10$ & $15 / 12-21 / 01$ & 05/09-1409 & $10 / 09$ & $21 / 09$ & $07 / 12-14 / 01$ \\
\hline IV & $\mathrm{Br}$ & $18 / 08-29 / 08$ & $24 / 08$ & 03/09 & $07 / 12-15 / 01$ & $02 / 08-13 / 08$ & 08/08 & $19 / 08$ & $21 / 11-07 / 01$ \\
\hline $\mathrm{V}$ & $\mathrm{Br}$ & $13 / 09-23 / 09$ & $21 / 09$ & $30 / 09$ & $01 / 01-28 / 01$ & 01/09-11/09 & 08/09 & $17 / 09$ & $21 / 12-14 / 01$ \\
\hline VI & $\mathrm{Br}$ & 03/08-09/08 & 07/08 & $17 / 08$ & $21 / 11-07 / 12$ & $18 / 07-25 / 07$ & $22 / 07$ & $02 / 08$ & $01 / 11-01 / 12$ \\
\hline VII & $\mathrm{Br}$ & $14 / 08-21 / 08$ & $17 / 08$ & $28 / 08$ & $21 / 12-07 / 03$ & $02 / 08-10 / 08$ & 05/08 & $17 / 08$ & $14 / 12-01 / 03$ \\
\hline VIII & $\mathrm{Br}$ & 09/09-14/09 & $11 / 09$ & $16 / 09$ & $15 / 12-01 / 03$ & $25 / 08-30 / 08$ & $28 / 08$ & 06/09 & $01 / 12-21 / 02$ \\
\hline IX & $\mathrm{Br}$ & $15 / 09-26 / 09$ & $20 / 09$ & $03 / 10$ & $21 / 12-21 / 01$ & $31 / 08-12 / 09$ & 05/09 & $19 / 09$ & $07 / 12-14 / 01$ \\
\hline $\mathrm{X}$ & $\mathrm{Br}$ & $18 / 09-25 / 09$ & $21 / 09$ & $02 / 10$ & $07 / 01-28 / 01$ & 03/09-11/09 & 06/09 & $18 / 09$ & $21 / 12-07 / 01$ \\
\hline XI & $\mathrm{Rx}^{*}$ & 29/08-08/09 & $05 / 09$ & $14 / 10$ & $15 / 12-07 / 03$ & $16 / 08-27 / 08$ & $23 / 08$ & 03/09 & $01 / 12-21 / 02$ \\
\hline
\end{tabular}

$\mathrm{Br}=$ branca; $\mathrm{Rx}=$ roxa. 
TABELA 2-Tamanho do fruto (TF), forma do fruto (FF), cor e espessura da película, e cor e sabor da polpa predominantes dos frutos colhidos das plantas selecionadas em Wenceslau Braz-MG / Períodos de 1996-1997 e 1997-1998.

\begin{tabular}{|c|c|c|c|c|c|c|}
\hline \multirow[b]{2}{*}{ Seleção } & \multirow[b]{2}{*}{ TF } & \multirow[b]{2}{*}{ FF } & \multicolumn{2}{|l|}{ Película } & \multicolumn{2}{|c|}{ Polpa } \\
\hline & & & cor & espessura & cor & sabor \\
\hline I & médio & redonda & roxa & fina & amarela & doce-acidulada \\
\hline II & grande & ovalada & roxa & fina & vermelha & doce \\
\hline III & médio & redonda & vermelha & fina & vermelha & ácida \\
\hline IV & pequeno & redonda & vermelha c/fundo amarelo & fina & amarela & doce \\
\hline $\mathbf{V}$ & pequeno & redonda & dourada & fina & amarela & doce \\
\hline VI & médio & redonda & vermelha & grossa & vermelha & sem sabor \\
\hline VII & médio & redonda & roxa & fina & amarela & doce-acidulada \\
\hline VIII & médio & redonda & roxa & fina & amarela & doce-acidulada \\
\hline IX & médio & redonda & vermelha c/fundo amarelo & fina & amarela & doce \\
\hline $\mathbf{X}$ & grande & ovalada & amarelo- esverdeada & grossa & amarela & ácida \\
\hline $\mathbf{X I}$ & pequeno & redonda-ovalada & roxa & grossa & roxa & doce \\
\hline
\end{tabular}

\section{CONCLUSÕES}

1- Alguns clones apresentaram características favoráveis em floração e frutificação, propiciando a seleção de plantas promissoras com produção precoce e tardia.

2- Com relação à duração da colheita, as plantas avaliadas mostraram ter ciclo curto, médio ou longo.

3- As plantas selecionadas poderão ser promissoras para a multiplicação vegetativa e/ou para cruzamentos, buscando a sua melhoria e posterior distribuição para plantios comerciais.

\section{REFERÊNCIAS}

AGRIANUAL 2006: anuário da agricultura brasileira. São Paulo: FNP Consultoria, 2007. p.182.

ALVARENGA, L.R.; FORTES, J.M. Cultivares de fruteiras de clima temperado. Informe Agropecuário, Belo Horizonte, v.11, n.124, p.3-24, 1985.

ANTUNES, L.E.C.; REGINA, M.de A.; ABRAHÃO, E.; ALVARENGA, A.A.; RESENDE, S.R. de; NUNES, J.M.S.; SILVA, V. J. da; OLIVEIRA, N. C. de. Pessegueiro e Ameixeira. Informe Agropecuário, Belo Horizonte, v.18, n.189, p. 18-23, 1997.

BARBOSA, W.; DALL'ORTO, F.A.C.; OJIMA, M.; MARTINS, F.P.; SANTOS, R.R. dos; SABINO, J.C. Polinização das fruteiras de caroço: ameixeira, nectarineira e pessegueiro. O Agronômico, Campinas, v.43, n.1, p.3-13, 1991.

CARVALHO, T.C.P. de; RASEIRA, M.D.B. Aspectos relacionados a polinização e autocompatibilidade em ameixeira japonesa (Prunus salicina Lindl.). Horti Sul, Pelotas, v.l, n.2, p.29-32, 1990.
CASTRO, L.A.S. Ameixa produção. Pelotas: Embrapa-SPI, 2003. 115p. (Frutas do Brasil; 43).

CHITARRA, M.I.F.; CHITARRA, A.B. Pós-colheita de frutas e hortaliças: fisiologia e manuseio. 2. ed. Lavras: UFLA, 2005. 785p.

GRELLMANN, E.; SIMONETTO, P.R. Dados de fenologia e produção de cultivares de ameixeira (Prunus salicina Lindl.). Porto Alegre: FEPAGO, 1995. 11p. (Circular Técnica, 3).

HERTER, F.G.; ZANOL, G.C.; REISSER JÚNIOR, C. Pessegueiro e Ameixeira. Informe Agropecuário, Belo Horizonte, v.18, n.189, p. 18-23, 1997.

HERTER, F.G; CARVALHO, F.L.C.; CASTRO, L.A.S. de; FLORES, C.A. Condições de clima e solo para a instalação do pomar. In: CASTRO, L.A.S. (Ed.). Ameixa produção. Pelotas: Embrapa-SPI, 2003. p.19-23 (Frutas do Brasil, 43).

LORENZI, H.; SARTORI, S.F.; BACHER, L.B.; LAERDA, M.T.C. de. Frutas brasileiras e exóticas cultivadas (de consumo in natura). São Paulo: Instituto Plantarum, 2006. 672p.

NASCIMENTO, L.M. Fisiologia pós-colheita dos frutos de quatro cultivares de ameixas (Prunus sp) armazenados em diferentes condições. 1986, 86f. Tese (Doutorado) - Universidade Federal de Lavras, Lavras, 1986.

OJIMA, M.;CAMPO-DALL'ORTO, F.A.; BARBOSA, W.; RIGITANO, O. Cultivares de ameixeira para o Estado de São Paulo. São Paulo: IAC, 1992. 16p. (Boletim Técnico, 144).

SILVA, F.P.da. Comportamento de cultivares de ameixeira (Prunus salicina Lindl.) em Caldas-MG. 2000. 93f. Tese (Doutorado) Universidade Federal de Lavras, Lavras, 2000. 